\title{
Human Bioclimatic Conditions, Trends, and Variability in the Athens University Campus, Greece
}

\author{
Panagiotis T. Nastos $^{1}$ and Andreas Matzarakis ${ }^{2}$ \\ ${ }^{1}$ Laboratory of Climatology and Atmospheric Environment, Department of Geography and Climatology, \\ Faculty of Geology and Geoenvironment, University of Athens, Panepistimioupolis, 15784 Athens, Greece \\ ${ }^{2}$ Meteorology and Climatology, University of Freiburg, Germany \\ Correspondence should be addressed to Panagiotis T. Nastos; nastos@geol.uoa.gr
}

Received 18 July 2013; Accepted 13 August 2013

Academic Editor: Tzu-Ping Lin

Copyright (C) 2013 P. T. Nastos and A. Matzarakis. This is an open access article distributed under the Creative Commons Attribution License, which permits unrestricted use, distribution, and reproduction in any medium, provided the original work is properly cited.

\begin{abstract}
The objective of this work is the assessment of human thermal bioclimatic conditions in the Athens University Campus (AUC), including the Faculties and their respective Departments of the largest state institution of higher learning in Greece, and among the largest universities in Europe. The analysis of bioclimate was carried out, using the physiologically equivalent temperature (PET), which is based on the energy balance model of the human body. The meteorological data required for the calculation of PET concern hourly values of air temperature, relative humidity, wind speed and total solar radiation, for the time period 19992007. The recorded data sets were obtained from the meteorological station of the Laboratory of Climatology and Atmospheric Environment of the University of Athens. The results revealed the hours of the day in which thermal comfort or stress prevails, as well as the trends and variability of PET, for the studied period. Finally, the intense heat waves occurred during summer 2007 along with extreme cold conditions during December 2003-February 2004 were analyzed in terms of PET classes and compared to the respective average bioclimatic conditions of the study period.
\end{abstract}

\section{Introduction}

Analysis of the human thermal environment is subject of special investigation among scientists serving at different disciplines such as climatologists, urban planners, architects, biologists, and physicians. A lot of human bioclimatic research has been carried out recently, indicating the impact of urban bioclimate on human morbidity [1-3], mortality [1-8], tourism potential and decision making [9-12], and urban planning [13-15]. Although a heat/cold wave is a meteorological event, it cannot be assessed without reference to its impacts on humans. An analysis of weather elements should always include the assessment of the human sensation of heat/cold [12]. Many thermal indices have been used, such as among others the Effective Temperature [16], the Discomfort Index by Thom [17] and the Cooling Power index $[18,19]$. Since 1938, Buttner [20] found that the total effects of all thermal components and not of a single meteorological parameter should be taken into account, in order to assess the thermal effect of environment on the human body. The necessity of modeling the human thermal balance led to the development of bioclimatic models, which are widely applied in bioclimatic studies, known as KLIMA-MICHELMODEL [21, 22] and MEMI [23]. Driscoll [24] refers to eleven independent indices, and, since then, Kalkstein and Valimont [25] and Höppe [26] have proposed further analysis. Following this effort, remarkable research has been carried out in order to formulate a reliable and user-friendly index for the assessment of the physiological thermal response of the human body to climatic conditions [27], but only Physiologically Equivalent Temperature (PET) and Universal Thermal Climate Index (UTCI) seem to meet these requirements. PET is recommended for the evaluation of the thermal component of different climates by VDI Guideline 3787 [28]. PET is based on the Munich Energy-balance Model for Individuals (MEMI), which describes the thermal conditions of the human body in a physiological relevant way $[29,30]$. The UTCI equivalent temperature for a particular set of wind, 
radiation, humidity, and air temperature parameters is then defined as the air temperature of the reference environment which produces the same strain index value as the actual conditions [31, 32].

The climate is already changing, and the intensity and frequency of extreme weather events, such as floods, heatwaves, and cold spells, may change in the future. Recent extreme weather events caused serious health and social problems in Europe, particularly in urban areas. These events will continue to pose additional challenges to health risk management and to the reliability of the power supply and other infrastructure. This demands a proactive and multidisciplinary approach by governments, agencies, and international organizations and improved interaction on all levels from local to international [33]. Europe experienced a deadly summer in 2003, when average summer temperatures were about $3^{\circ} \mathrm{C}$ higher than the long-term mean, and in major cities of Europe, the daily maximum temperature exceeded $35^{\circ} \mathrm{C}$ for more than a week, causing about 70,000 excess deaths in parts of southern, western, and central Europe [3436]. This is the reason that the German Weather Service, within the framework of the EuroHeat project [37], has developed a climate information decision support tool with medium-term heat forecasting, which maps the probability of a forthcoming heat-wave over Europe (http://www.euroheatproject.org/dwd/).

The purpose of the present study is the assessment and interpretation of human bioclimatic conditions in Athens University Campus, during the 1999-2007 period, based on PET human thermal index, which is irrespective of clothing and metabolic activity. Further, the heat waves occurred in summer 2007, and the cold spells during winter 2003/2004 were also analyzed and compared to the mean bioclimatic conditions.

\section{Data and Methodology}

The performed human biometeorological analysis in the Athens University Campus (AUC) was considered by the authors of great importance due to the large number of people involved in the AUC, during the entire year. National and Kapodistrian University of Athens is the largest state institution of higher learning in Greece and among the largest universities in Europe. With a student body of about 125000 undergraduate and postgraduate students, over 2000 members of academic staff, and approximately 1300 administrative and secretarial staff and specialized personnel, the University of Athens aims at excellence in both teaching and research in a significantly varied range of disciplines. Regarding the time distribution during the year of the mentioned crowd in the university campus, there are two semesters within the year, the first begins in September and ends in January and the second from February to July. During August, the university is closed due to summer holidays. Official holidays concern the Christmas and Easter holidays from December 24 to January 7 and fifteen days in April or May, respectively. Further, there are a few sparse individual days off, due to national celebrations such as October 28 and
March 25. Thus, in general, the campus is not crowded fifteen days in winter, fifteen days in spring, and the whole August.

The meteorological data used in the study were acquired from the meteorological station of the Laboratory of Climatology and Atmospheric Environment, University of Athens (latitude: $37^{\circ} 58^{\prime} \mathrm{N}$, longitude: $23^{\circ} 47^{\prime} \mathrm{E}$, and altitude: $257 \mathrm{~m}$ ) and concern hourly values of air temperature, relative humidity, total solar radiation, and wind speed for the period 1999-2007. In this point we have to remark that the time series of the meteorological data had been interrupted after 2007 for long consecutive spells, due to technical reasons. This is why we considered the 9 -year period as the one with the most reliable meteorological data sets for the performed analysis. The location of the meteorological station in AUC along with a satellite image of the greater Athens area is depicted in Figure 1.

For bioclimatic purposes, the wind speed was adjusted according to the following formula [38]:

$$
\mathrm{WS}_{1.1}=\mathrm{WS}_{h} *\left(\frac{1.1}{h}\right)^{\alpha} \quad \alpha=0.12 * z_{0}+0.18
$$

where $\mathrm{WS}_{h}$ is the wind speed $\left(\mathrm{ms}^{-1}\right)$ at the anemometer height ( $h$, usually $10 \mathrm{~m}$ a.g.l.), $\alpha$ is an empirical exponent, depending on the surface roughness, and $z_{0}$ is the roughness length. Wind velocity was estimated at $1.1 \mathrm{~m}$, which is the center of gravity of the human body and builds the reference level for human biometeorological studies. In this study, the value of roughness length $z_{0}=0.25$ was applied, depending on the landscape around the examined station. The aforementioned value of roughness length for a specific terrain was derived from the European Wind Atlas [39].

The quantification of human bioclimatic conditions was achieved using the Physiologically Equivalent Temperature (PET), at a given place (outdoors or indoors). It is equivalent to the air temperature at which-in a typical indoor setting (without wind and solar radiation) - the heat balance of the human body (work metabolic rate $80 \mathrm{~W}$ of light activity, that should be added to the basic metabolic rate $86.5 \mathrm{~W}$, [40]; heat resistance of clothing $0.9 \mathrm{clo}$, which is the reference clothing insulation value used for the formulation of PET) is maintained with core and skin temperatures equal to those of the under assessment conditions [26, 41]. The following assumptions are made for indoor reference climate: mean radiant temperature equals air temperature $\left(T_{\mathrm{mrt}}=T_{a}\right)$. Air velocity is set to $0.1 \mathrm{~m} / \mathrm{s}$. Water vapour pressure is set to $12 \mathrm{hPa}$ (approximately equivalent to relative humidity of $50 \%$ at $T_{a}=20^{\circ} \mathrm{C}$ ). The PET assessment scale (Table 1) is derived by calculating Fanger's [29] PMV for varying air temperatures in the reference environment using the settings for the PET reference person (height: $1.75 \mathrm{~m}$, weight: $75 \mathrm{~kg}$, age: $35 \mathrm{yrs}$, and sex: male; work metabolic rate $80 \mathrm{~W}$ of light activity, that should be added to the basic metabolic rate and heat resistance of clothing 0.9 clo) [42]. According to Höppe [26], the assumption of constant values for clothing and activity in the calculation of PET was made in order to define an index independent of individual behavior. 


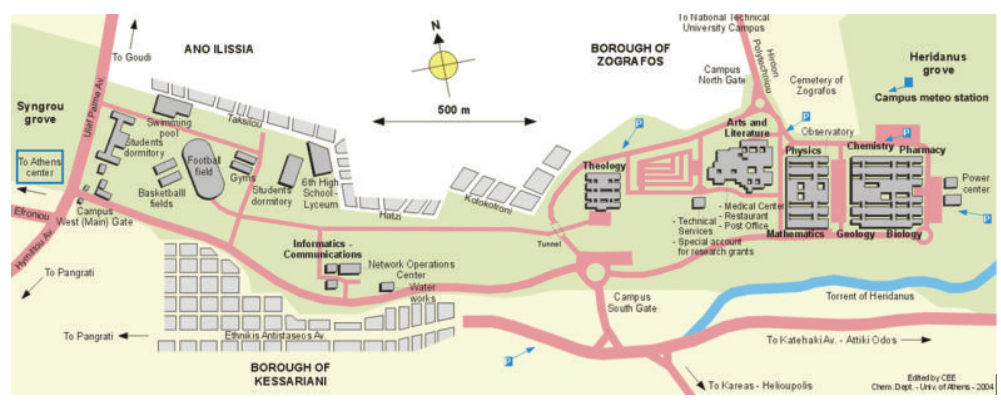

(a)

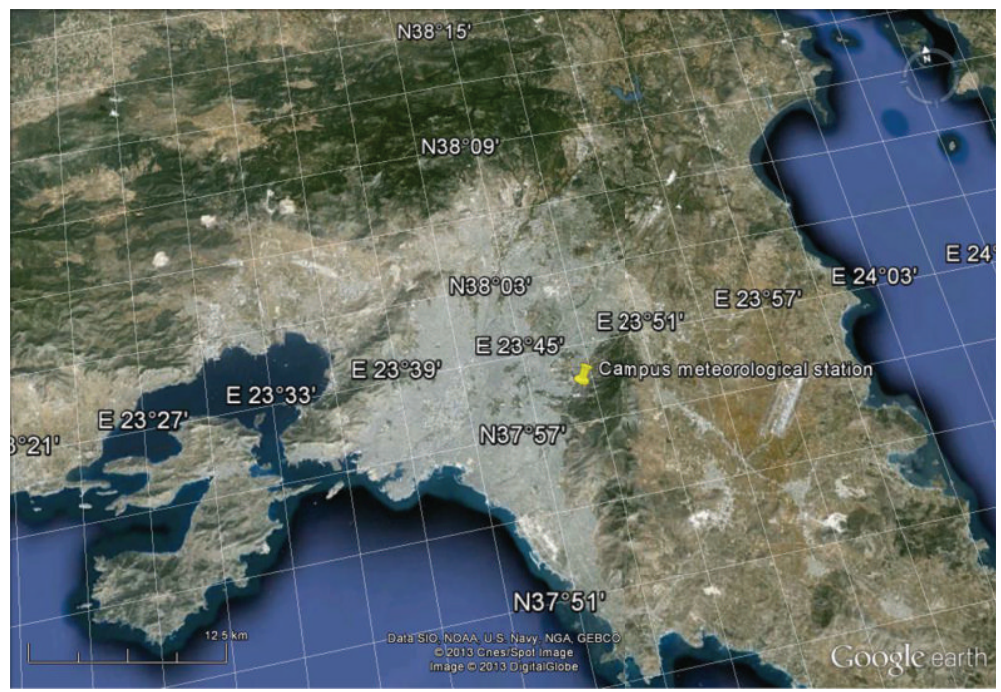

(b)

Figure 1: Athens University Campus (a) and satellite image of the wider Athens area (b) with the marked site of the campus meteorological station.

TABLE 1: Physiologically Equivalent Temperature (PET) for different grades of thermal sensation and physiological stress on human beings [42].

\begin{tabular}{lcc}
\hline PET $\left({ }^{\circ} \mathrm{C}\right)$ & Thermal sensation & Physiological stress level \\
\hline$<4$ & Very cold & Extreme cold stress \\
$4-8$ & Cold & Strong cold stress \\
$8-13$ & Cool & Moderate cold stress \\
$13-18$ & Slightly cool & Slight cold stress \\
$18-23$ & Comfortable & No thermal stress \\
$23-29$ & Slightly warm & Slight heat stress \\
$29-35$ & Warm & Moderate heat stress \\
$35-41$ & Hot & Strong heat stress \\
$>41$ & Very hot & Extreme heat stress \\
\hline
\end{tabular}

PET was calculated using "RayMan" model, appropriate to calculate radiative heat transfer and human biometeorological indices [42, 43]. The "RayMan" model, developed according to Guideline 3787 of the German Engineering Society [28], calculates the radiative heat transfer in both simple and complex environments. Finally, the use of pivot diagrams was considered necessary to demonstrate the frequency (\%) of PET classes, in order to interpret the bioclimatic patterns prevailing in different time scales. The time used in the analysis concerns local time, thus UTC + $2 \mathrm{~h}$.

\section{Results and Discussion}

3.1. Human Bioclimatic Conditions in Athens University Campus. The mean PET within the examined period (19992007) was found $14.6^{\circ} \mathrm{C}$, while the absolute maximum PET was $54.8^{\circ} \mathrm{C}$ in June 24,2007 , at 15:00, and the absolute minimum PET was $-15.5^{\circ} \mathrm{C}$ in February 14, 2004, at 07:00. These high/low figures of PET characterize the extreme heat stress, appeared during the heat waves in summer 2007 and the extreme cold stress in the very cold winter 2004, respectively. In addition, the mean frequency of days, within the examined period, with strong and extreme heat stress $\left(\mathrm{PET}>35^{\circ} \mathrm{C}\right)$, thermal comfort and slight heat stress $\left(18^{\circ} \mathrm{C}<\right.$ $\left.\mathrm{PET}<29^{\circ} \mathrm{C}\right)$, and strong and extreme cold stress $\left(\mathrm{PET}<8^{\circ} \mathrm{C}\right)$ was calculated, and the results are presented in Table 2.

The daily minimum figures of PET, occurring at night, were taken into account in order to estimate the frequency of days with strong and extreme cold stress against daily maximum PET for the other classes of PET. About $50 \%$ of 
TABLE 2: Mean frequency (days) of characteristic thresholds of PET, within the period 1999-2007.

\begin{tabular}{lccc}
\hline & $\mathrm{PET}<8^{\circ} \mathrm{C}$ & $18^{\circ} \mathrm{C}<\mathrm{PET}<29^{\circ} \mathrm{C}$ & $\mathrm{PET}>35^{\circ} \mathrm{C}$ \\
\hline Frequency (days) & 187.1 & 98.5 & 114.3 \\
\hline
\end{tabular}

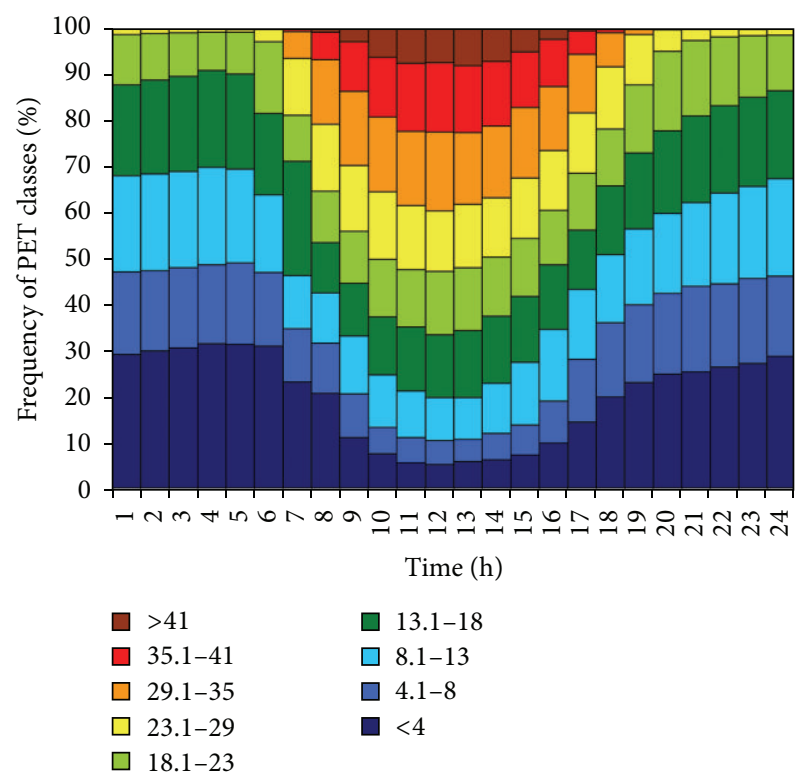

Figure 2: Bioclimatic diagram for Athens University Campus for the period 1999-2007; frequencies (\%) of the nine PET classes for each hour of the mean day.

the nights of the year were related to strong/extreme cold bioclimatic conditions, which is very likely due to AUC which is lying out of the urbanized area and on the foothills of Hymettus Mountain. Approximately $30 \%$ of the days of the year were associated with strong/extreme heat stress and thermal comfort or slight heat stress appeared in almost $27 \%$ of the days.

The human bioclimatic conditions are presented in terms of PET classes (\%) for each hour of the day (Figure 2) and for 10 -days period (Figure 3 ) in the respective diagrams. These bioclimatic diagrams provide very clear and in a simple way the bioclimatic information for the area concerned. Figure 2 reveals that approximately $45 \%-65 \%$ of days, from $08: 00$ in the morning to 17:00 in the afternoon, depict PET greater than $18^{\circ} \mathrm{C}$ (thermal comfort). Further, for about $13 \%-23 \%$ of days, the environment is characterized by strong/extreme heat stress from 09:00 in the morning till 16:00 in the afternoon. Regarding the strong/extreme cold stress, it appears for almost $50 \%$ of days from midnight to early morning hours (06:00).

The frequency distribution of PET classes in 10-day period is depicted in Figure 3. Here, it should be noted that the results shown in the diagram concern mean daily figures of PET. Since the first 10 days of June up to the second 10 days of September, $45 \%-85 \%$ of the days within the examined period are associated with PET greater than $18^{\circ} \mathrm{C}$ (threshold for thermal comfort). Regarding the strong/extreme heat

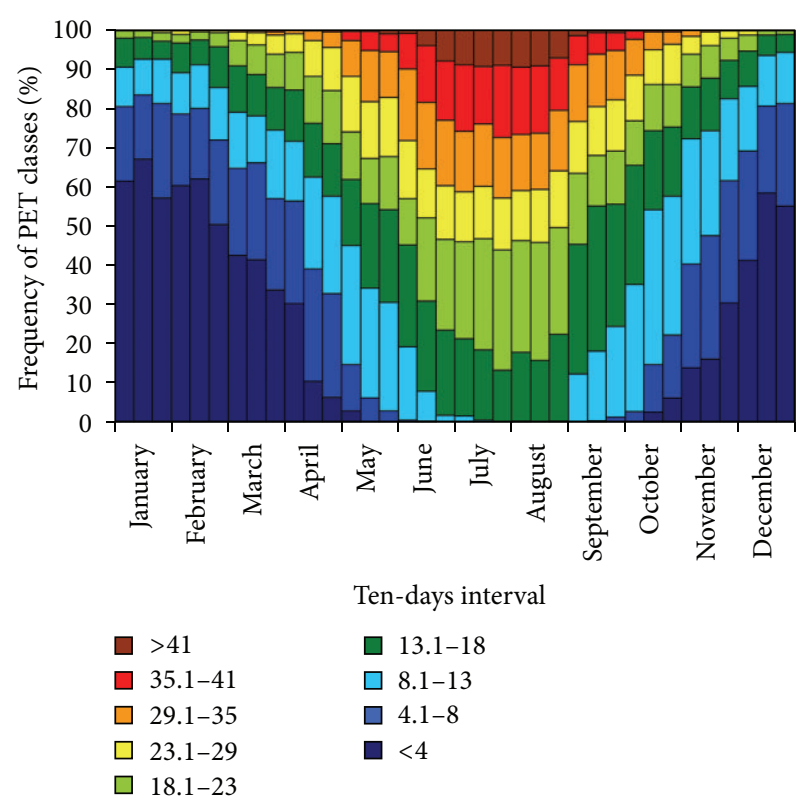

FIgURE 3: Bioclimatic diagram for Athens University Campus for the period 1999-2007; frequencies (\%) of the nine PET classes for 10 -day period of the mean year.

stress $\left(\mathrm{PET}>35^{\circ} \mathrm{C}\right.$ ), it appears in almost $20 \%-25 \%$ of the days from the third 10 days of June to the third 10 days of August.

PET index has been used widely in the assessment of human bioclimatic conditions. More specifically, Thorsson et al. [15] and Gulyás et al. [44] have applied PET in urban built-up area with complex shading patterns and generated accurate predictions of thermal environments. Outdoor thermal environment is impacted by the built environment, for example, anthropogenic heat, evaporation and evapotranspiration of plants, shading by trees and man-made objects [45], and ground surface covering, such as natural grass and artificial pavement. However, Lin [46] concluded that in hot and humid regions few people visit squares or other public spaces when the thermal index is high. The largest numbers of people who visit squares are when the thermal condition is close to their thermal comfort range. Svensson et al. [47] presented the PET distribution map of Goteborg using the geographic information system. Gulyás et al. [44] evaluated thermal comfort in Szeged, Hungary. Bouyer et al. [48] evaluated the thermal comfort in two stadia (Stade de France, Paris, and the Atatürk olympic stadium, Istanbul), using wind tunnel experiments and PET.

Further to the above discussion, we must acknowledge a constraint related to the PET assessment scale. We used the PET scale for western/middle European countries taking into consideration that the greater Athens area has a temperate climate, not significantly different from the climate of western/middle European countries. Thus, the use of the PET assessment scale for western/middle European countries is almost acceptable, while a future work for the determination of PET assessment scale in Athens, Greece, is already in progress. A recent study by Cohen et al. [49] confirms our 


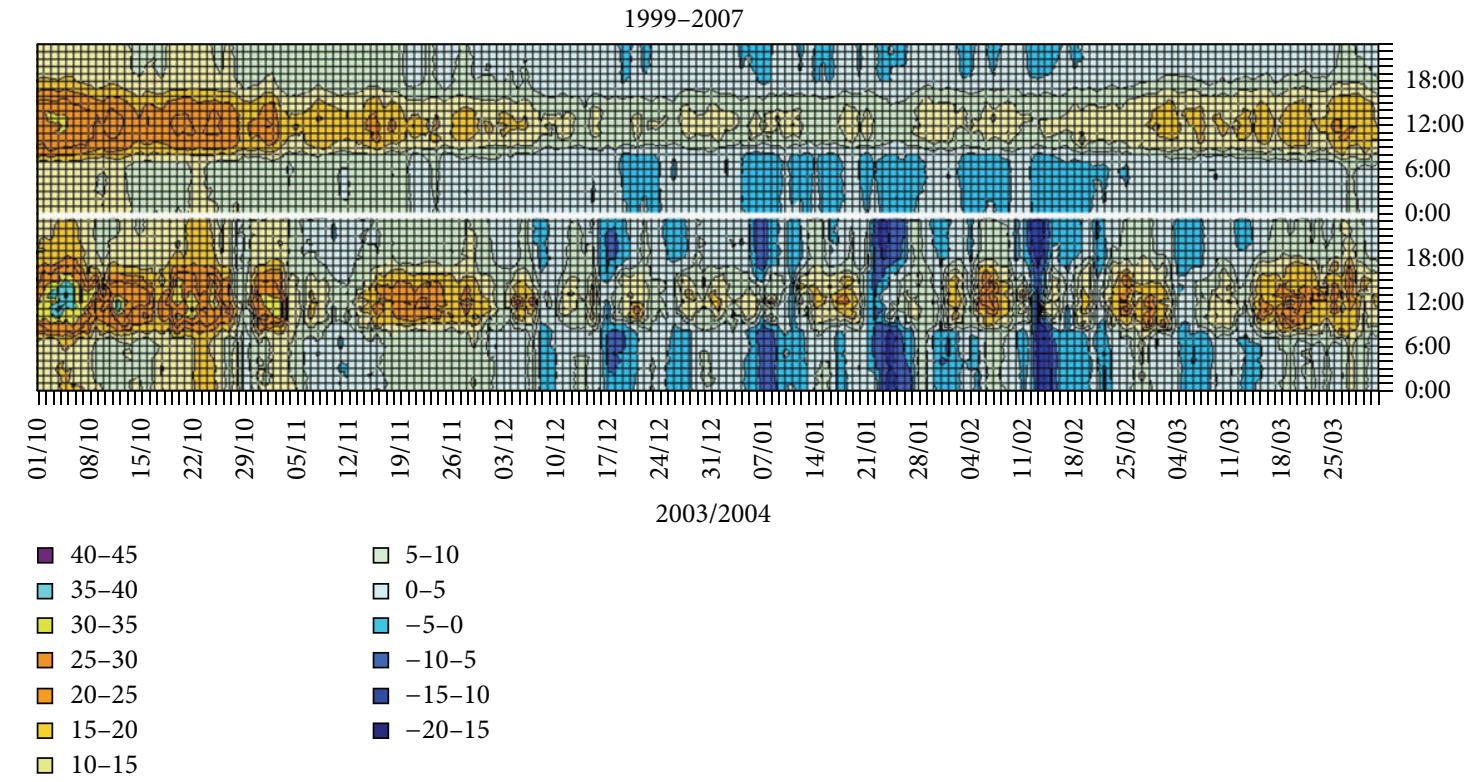

FIGURE 4: Composite mean hourly variability of PET within the cold period 1999-2007 (upper graph), along with the hourly variability of PET within the cold period 2003-2004 (lower graph).

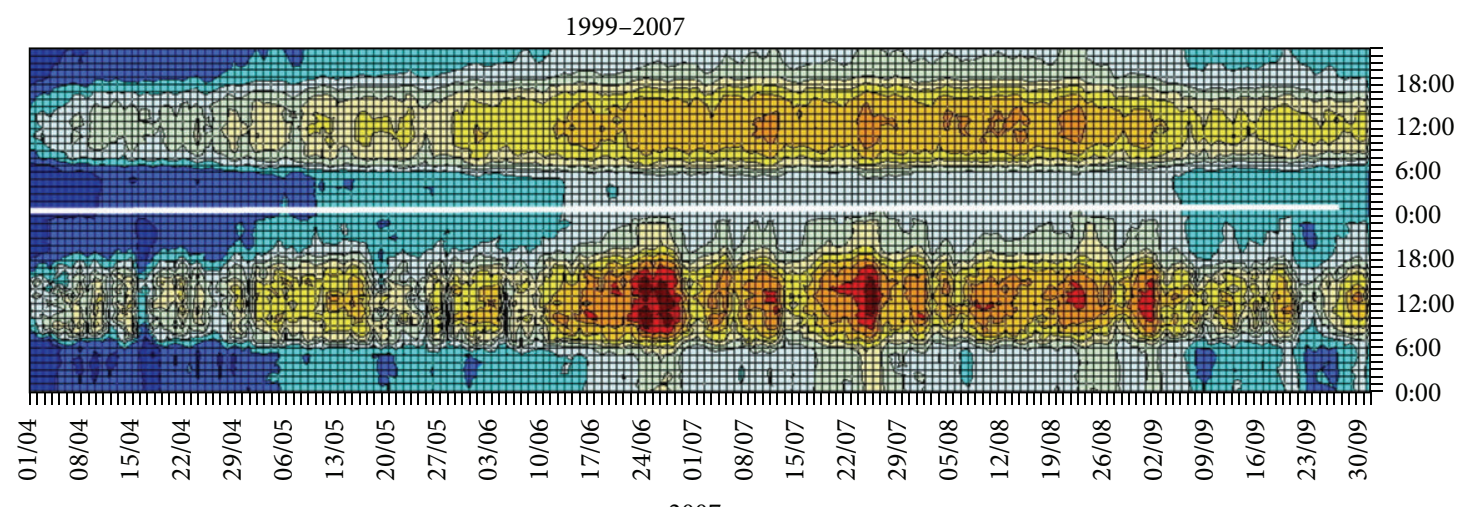

$\begin{array}{ll}\square 50-55 & \square 20-25 \\ \square 45-50 & \square 15-20 \\ \square 40-45 & \square 10-15 \\ \square 35-40 & \square 5-10 \\ \square 30-35 & \square 0-5 \\ \square 25-30 & \square-5-0\end{array}$

FIGURE 5: Composite mean hourly variability of PET within the warm period 1999-2007 (upper graph), along with the hourly variability of PET within the warm period 2007 (lower graph).

assumption, revealing that the acceptable comfort range of PET for the Mediterranean climate of Tel Aviv is $19-26^{\circ} \mathrm{C}$, against $18-23^{\circ} \mathrm{C}$ for the acceptable comfort range of PET for western/middle European countries. Besides, the assessment scale [42] is frequently used in international literature to estimate bioclimatic conditions in different places, such as Istanbul and Paris [48], Goteborg [47], Szeged [44], Matsudo (a satellite city near Tokyo), Japan [15], and Far-Eastern Federal District of the Russian Federation (temperate monsoon climate zone, which is characterized by an extreme continental regime of annual temperatures) [50].
3.2. Warm and Cold Periods of the Year-Heat Waves and Cold Spells. We analyzed on one hand the composite mean hourly variability of PET within the cold (October-March) and warm (April to September) periods of the year during 1999-2007, and on the other hand we compared these two composite periods with the corresponding periods of extremes, which appeared within the examined period, namely, the cold period 2003/2004 with the occurrence of two extreme cold spells and the warm period 2007, associated with three extreme heat waves. The results of the analysis are depicted in Figures 4 and 5. 
As far as the composite cold period is concerned, the bioclimatic conditions appeared to be cool to slightly warm from 08:00 in the morning until 17:00 in the afternoon, and this is evident from early October until late November and in March, as well. The thermal sensation was classified in cool to cold during the day, while the midnight hours were usually characterized by strong/extreme cold stress, from December to February (Figure 4, upper graph). Comparing the composite mean cold period with the corresponding cold period 2003-2004 (Figure 4, lower graph), the two extreme cold spells (January 22-24, 2004, and February 13-14, 2004) are obvious, and one could remark the very extreme low PET figures $\left(-20^{\circ} \mathrm{C}\right.$ to $\left.-15^{\circ} \mathrm{C}\right)$, appeared even during the whole day (this is the case of total frost).

During the composite warm period, the environment was characterized by strong/extreme heat stress from 08:00 in the morning until 17:00 in the afternoon, against thermal comfort to slightly heat stress for the rest of the day (Figure 5, upper graph). Analyzing the extreme warm period appeared in 2007 , the three cells corresponding to three extreme heat waves were revealed, which were recorded in June 2428, July 19-27 and August 22-24, in descending order of intensity, respectively. The thermal stress was very extreme (PET: $50^{\circ} \mathrm{C}-55^{\circ} \mathrm{C}$ ), and it was evident from 08:00 in the morning to 15:00 in the afternoon, especially for the first two heat waves (Figure 5, lower graph). It should be remarked here the duration of the heat waves concerning 8,6 , and 3 consecutive days, respectively, as well as the prevailing calm against the development of Etesian winds, which is normal event during summer in Greece. These winds are periodical winds of the north section established over the Aegean Sea, when a high pressure center in the central and south Europe is combined with the Indian low pressure system over Asia Minor and the Eastern Mediterranean Sea [51]. A characteristic effect of the Etesians regime is summer droughts and uniform weather conditions in Greece [52]. This prevailing weather type (cool and dry winds over the Aegean Sea) in summer moderates the intensity of heat stress affecting the population mainly living in urban areas.

3.3. Trends and Variability. In order to examine the variability and trends of PET extremes, the annual number of days with PET values above or below certain thresholds was estimated. The results are presented in Figure 6 and should be only considered as indicative of the PET variability, due to the short record of observations. The time series of annual number of days with $\mathrm{PET}>41^{\circ} \mathrm{C}$ (extreme heat stress) shows a statistically significant increasing trend $(P<0.05)$, which when combined with the projected climate change allows us to consider that the human bioclimatic conditions in the study area are likely to get worse. Further, the time series of annual number of days with PET $<4^{\circ} \mathrm{C}$ (extreme cold stress) showed similar statistically significant increasing trend $(P<0.05)$, indicating that the human bioclimatic conditions tend to become more extreme with respect to the cold component of thermal sensation. The time series of annual number of days with strong cold/heat stress did not show significant trends. Matzarakis and Nastos [53] have

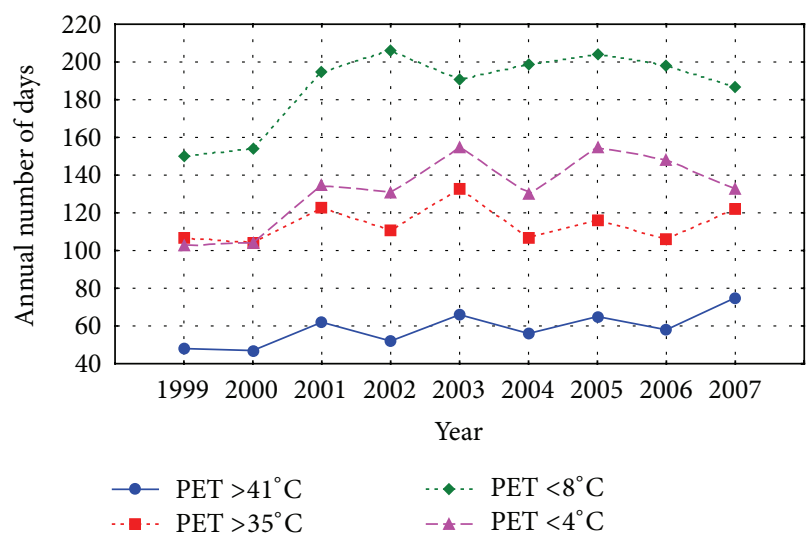

Figure 6: Annual number of days with PET $>41^{\circ} \mathrm{C}$, PET $>35^{\circ} \mathrm{C}$, $\mathrm{PET}<8^{\circ} \mathrm{C}$, and $\mathrm{PET}<4^{\circ} \mathrm{C}$.

revealed that the human thermal bioclimatic conditions are expected to change rapidly in summer, based on AlF scenario. The forthcoming changes concern increases in more than two or three heat stress classes for the summer, within the greater Athens area, while in winter, the expected changes are likely to range between one and two classes of heat stress.

\section{Conclusions}

The conducted analysis for the assessment of PET in the Athens University Campus, using bioclimatic diagrams, revealed the following findings.

(i) About $50 \%$ of the nights of the entire year were related to strong/extreme cold bioclimatic conditions, against almost $30 \%$ of the days associated with strong/extreme heat stress. Thermal comfort or slight heat stress appeared in almost $27 \%$ of the days.

(ii) The outdoor thermal environment was characterized by strong/extreme heat stress from 09:00 in the morning till 16:00 in the afternoon for approximately $13 \%-23 \%$ of days. Regarding strong/extreme cold stress, it appears for almost $50 \%$ of days from midnight to early morning hours (06:00).

(iii) The outdoor thermal environment remains above thermal comfort (PET $>18^{\circ} \mathrm{C}$ ) for approximately $45 \%-65 \%$ of days, from 08:00 in the morning to $17: 00$ in the afternoon.

(iv) The period from the beginning of June until the middle of September is characterized by PET $>18^{\circ} \mathrm{C}$ concerning $45 \%-85 \%$ of the days, while strong/extreme heat stress $\left(\mathrm{PET}>35^{\circ} \mathrm{C}\right.$ ) appeared in almost $20 \%-25 \%$ of the days from the end of June to the end of August.

(v) During the warm period of the year, the thermal environment was characterized by strong/extreme heat stress from 08:00 in the morning until 17:00 in the afternoon, while during the cold period of the year, the bioclimatic conditions appeared to be cool to 
slightly warm from 08:00 in the morning until 17:00 in the afternoon, and this is evident from early October until late November and in March.

The trend analysis of PET extremes indicated increasing trends for both extreme heat/cold stress. Besides, taking into consideration the extreme heat waves in summer 2007 and extreme cold spells in winter 2003-2004, the authors are aware that the application of human biometeorological indices against single meteorological parameters in the assessment of heat/cold waves would contribute more effectively in addressing and mitigating such extreme circumstances. This is very crucial in crowded areas, where outdoor activities are imposed daily, and this is the case of Athens University Campus.

\section{Acknowledgment}

This research has been partially funded by the Special Account for Research Grants of the University of Athens.

\section{References}

[1] J. Schwartz, J. M. Samet, and J. A. Patz, "Hospital admissions for heart disease: the effects of temperature and humidity," Epidemiology, vol. 15, no. 6, pp. 755-761, 2004.

[2] P. T. Nastos and A. Matzarakis, "Weather impacts on respiratory infections in Athens, Greece," International Journal of Biometeorology, vol. 50, no. 6, pp. 358-369, 2006.

[3] P. Michelozzi, U. Kirchmayer, K. Katsouyanni et al., "Assessment and prevention of acute health effects of weather conditions in Europe, the PHEWE project: background, objectives, design," Environmental Health, vol. 6, article 12, 2007.

[4] F. C. Curriero, K. S. Heiner, J. M. Samet, S. L. Zeger, L. Strug, and J. A. Patz, "Temperature and mortality in 11 cities of the eastern United States," American Journal of Epidemiology, vol. 155, no. 1, pp. 80-87, 2002.

[5] A. Analitis, K. Katsouyanni, A. Biggeri et al., "Effects of cold weather on mortality: results from 15 European cities within the PHEWE project," American Journal of Epidemiology, vol. 168, no. 12, pp. 1397-1408, 2008.

[6] M. Baccini, A. Biggeri, G. Accetta et al., "Heat effects on mortality in 15 European cities," Epidemiology, vol. 19, no. 5, pp. 711-719, 2008.

[7] S. P. Almeida, E. Casimiro, and J. Calheiros, "Effects of apparent temperature on daily mortality in Lisbon and Oporto, Portugal," Environmental Health, vol. 9, no. 1, article 12, 2010.

[8] P. T. Nastos and A. Matzarakis, "The effect of air temperature and human thermal indices on mortality in Athens, Greece," Theoretical and Applied Climatology, vol. 108, no. 3-4, pp. 591599, 2012.

[9] C. R. De Freitas, “Tourism climatology: evaluating environmental information for decision making and business planning in the recreation and tourism sector," International Journal of Biometeorology, vol. 48, no. 1, pp. 45-54, 2003.

[10] E. A. Didaskalou and P. T. Nastos, "The role of climatic and bioclimatic conditions in the development of health tourism product," Anatolia, vol. 14, no. 2, pp. 107-126, 2003.

[11] J. M. Hamilton and M. A. Lau, "The role of climate information in tourist destination choice decision-making," in Proceedings of the 17th International Congress of Biometeorology, pp. 608-611, 2005.

[12] A. Matzarakis and P. T. Nastos, "Analysis of tourism potential for Crete Island, Greece," Global Nest Journal, vol. 13, pp. 141149, 2011.

[13] M. Nikolopoulou and S. Lykoudis, "Thermal comfort in outdoor urban spaces: analysis across different European countries," Building and Environment, vol. 41, no. 11, pp. 1455-1470, 2006.

[14] S. Thorsson, M. Lindqvist, and S. Lindqvist, "Thermal bioclimatic conditions and patterns of behaviour in an urban park in Göteborg, Sweden," International Journal of Biometeorology, vol. 48, no. 3, pp. 149-156, 2004.

[15] S. Thorsson, T. Honjo, F. Lindberg, I. Eliasson, and E. M. Lim, "Thermal comfort and outdoor activity in Japanese urban public places," Environment and Behavior, vol. 39, no. 5, pp. 660684, 2007.

[16] B. Givoni, Man, Climate and Architecture, Elsevier, Amsterdam, Netherlands, 1969.

[17] E. Thom, “The discomfort index," Weatherwise, vol. 12, pp. 5760, 1959.

[18] P. A. Siple and C. F. Passel, "Measurements of dry atmospheric cooling in subfreezing temperatures," Proceedings of the American Philosophical Society, vol. 89, pp. 177-199, 1945.

[19] A. S. Tzenkova, I. M. Kandjov, and J. N. Ivancheva, "Some biometeorological aspects of urban climate in Sofia," in Proceedings of 5 th International Conference on Urban Climate, vol. 2, pp. 103-106, Lodz, Poland, 2003.

[20] K. Buttner, Physikalische Bioklimatologie, Akademische Verlagsgesellschaft, 1938.

[21] P. O. Fanger, Thermal Comfort, McGraw-Hill, New York, NY, USA.

[22] G. Jendritzky, "Bioklimatische Bewertungsgrundlage zur Beschreibung des thermischen Milieus in der Stadt- und Landschaftsplanung," ARL Beitrdge 128, 1990.

[23] P. Höppe, Die Energiebilanz des Menschen, vol. 49, Meteorologisches Institut, Universitat Munchen, 1984.

[24] D. M. Driscoll, "Human health," in Handbook of Applied Meteorology, D. D. Houghton, Ed., pp. 778-814, John Wiley and Sons, 1985.

[25] L. S. Kalkstein and K. M. Valimont, "An evaluation of summer discomfort in the United States using a relative climatological index," Bulletin of American Meteorological Society, vol. 67, no. 7, pp. 842-848, 1986.

[26] P. Höppe, “The physiological equivalent temperature-a universal index for the biometeorological assessment of the thermal environment," International Journal of Biometeorology, vol. 43, no. 2, pp. 71-75, 1999.

[27] F. R. d’Ambrosio Alfano, B. I. Palella, and G. Riccio, “Thermal environment assessment reliability using temperaturehumidity indices," Industrial Health, vol. 49, no. 1, pp. 95-106, 2011.

[28] VDI, VDI, 3787, Part I: Environmental Meteorology, Methods for the Human Biometeorological Evaluation of Climate and Air Quality for the Urban and Regional Planning at Regional Level. Part I: Climate, Beuth, Berlin, Germany, 1998.

[29] P. O. Fanger, Thermal Comfort, McGraw-Hill, New York, NY, USA, 1972.

[30] P. Höppe, "Heat balance modeling," Experentia, vol. 49, pp. 741746, 1993. 
[31] G. Jendritzky, G. Havenith, P. Weihs, E. Batchvarova, and R. de Dear, "The universal thermal climate index UTCI-goal and state of COST action 730 and ISB commission 6," in Proceedings of the 18th International Congress of Biometeorology (ICB '08), Tokyo, Japan, Septembe 2008.

[32] D. Fiala, G. Havenith, P. Bröde, B. Kampmann, and G. Jendritzky, "UTCI-Fiala multi-node model of human heat transfer and temperature regulation," International Journal of Biometeorology, vol. 56, no. 3, pp. 429-441, 2012.

[33] WHO Regional Office for Europe, Budapest Declaration, 2004, http://www.euro.who.int/document/e83335.pdf.

[34] J. M. Robine, S. L. K. Cheung, S. Le Roy et al., "Death toll exceeded 70,000 in Europe during the summer of 2003," Comptes Rendus, vol. 331, no. 2, pp. 171-178, 2008.

[35] C. Schär, P. L. Vidale, D. Lüthi et al., "The role of increasing temperature variability in European summer heatwaves," Nature, vol. 427, no. 6972, pp. 332-336, 2004.

[36] S. Vandentorren, P. Bretin, A. Zeghnoun et al., "August 2003 heat wave in France: risk factors for death of elderly people living at home," European Journal of Public Health, vol. 16, no. 6, pp. 583-591, 2006.

[37] WHO, "Improving public health responses to extreme weather/heat-waves-EuroHEAT," Technical Summary, 2009.

[38] W. Kuttler, "Stadtklima," in Handbuch der Umweltveränderungen und Ökotoxologie. Band 1B: Atmosphäre (Hrsg.), R. Guderian, Ed., pp. 420-470, Springer, 2000.

[39] I. Troen and E. L. Petersen, European Wind Atlas, Risø National Laboratory, Roskilde, Denmark, 1989.

[40] J. A. J. Stolwijk and J. D. Hardy, "Control of body temperature," in Handbook of Physiology, Section 9, Reactions to Environmental Agents, H. K. Douglas and M. D. Bethesda, Eds., pp. 45-69, American Physiological Society, 1977.

[41] H. Mayer and P. Höppe, "Thermal comfort of man in different urban environments," Theoretical and Applied Climatology, vol. 38, no. 1, pp. 43-49, 1987.

[42] A. Matzarakis, H. Mayer, and M. G. Iziomon, "Applications of a universal thermal index: physiological equivalent temperature," International Journal of Biometeorology, vol. 43, no. 2, pp. 76-84, 1999.

[43] A. Matzarakis, F. Rutz, and H. Mayer, "Modelling radiation fluxes in simple and complex environments: basics of the RayMan model," International Journal of Biometeorology, vol. 54, no. 2, pp. 131-139, 2010.

[44] Á. Gulyás, J. Unger, and A. Matzarakis, "Assessment of the microclimatic and human comfort conditions in a complex urban environment: modelling and measurements," Building and Environment, vol. 41, no. 12, pp. 1713-1722, 2006.

[45] T. P. Lin, A. Matzarakis, and R. L. Hwang, "Shading effect on long-term outdoor thermal comfort," Building and Environment, vol. 45, no. 1, pp. 213-221, 2010.

[46] T. P. Lin, "Thermal perception, adaptation and attendance in a public square in hot and humid regions," Building and Environment, vol. 44, no. 10, pp. 2017-2026, 2009.

[47] M. K. Svensson, S. Thorsson, and S. Lindqvist, "A geographical information system model for creating bioclimatic mapsexamples from a high, mid-latitude city," International Journal of Biometeorology, vol. 47, no. 2, pp. 102-112, 2003.

[48] J. Bouyer, J. Vinet, P. Delpech, and S. Carré, “Thermal comfort assessment in semi-outdoor environments: application to comfort study in stadia," Journal of Wind Engineering and Industrial Aerodynamics, vol. 95, no. 9-11, pp. 963-976, 2007.
[49] P. Cohen, O. Potchter, and A. Matzarakis, "Human thermal perception of Coastal Mediterranean outdoor urban," Applied Geography, vol. 37, pp. 1-10, 2012.

[50] E. Grigorieva and A. Matzarakis, "Physiologically equivalent temperature as a factor for tourism in extreme climate regions in the Russian Far East: preliminary results," European Journal of Tourism, Hospitality and Recreation, vol. 3, pp. 127-142, 2011.

[51] D. A. Metaxas and A. Bartzokas, "Pressure covariability over the Atlantic, Europe and N. Africa. application: centers of action for temperature, winter precipitation and summer winds in Athens, Greece," Theoretical and Applied Climatology, vol. 49, no. 1, pp. 9-18, 1994.

[52] P. T. Nastos, C. M. Philandras, and C. C. Repapis, "Application of canonical analysis to air temperature and precipitation regimes over Greece," Fresenius Environmental Bulletin, vol. 11, no. 8, pp. 488-493, 2002.

[53] A. Matzarakis and P. T. Nastos, "Heat waves in Athens," in Proceedings of the 8th Hellenic Conference on Meteorology, Climatology and Atmospheric Physics, vol. 3, pp. 153-160, Athens, Greece, May 2006. 

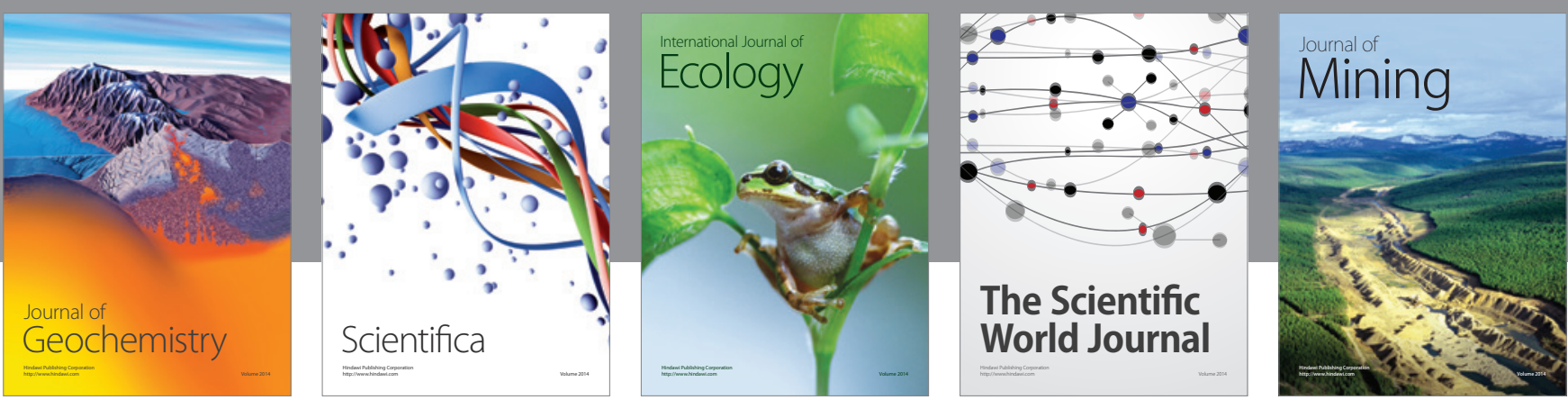

The Scientific World Journal
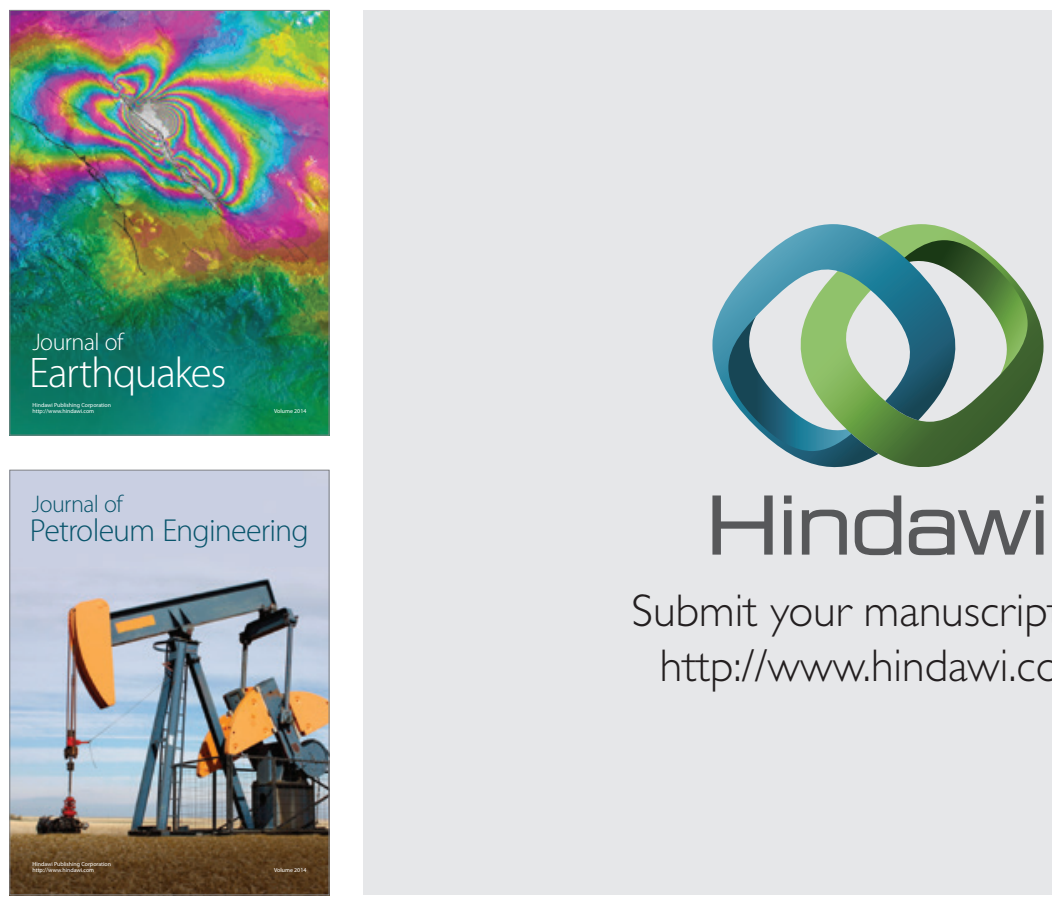

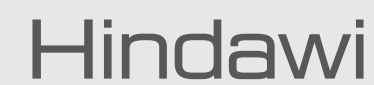

Submit your manuscripts at

http://www.hindawi.com
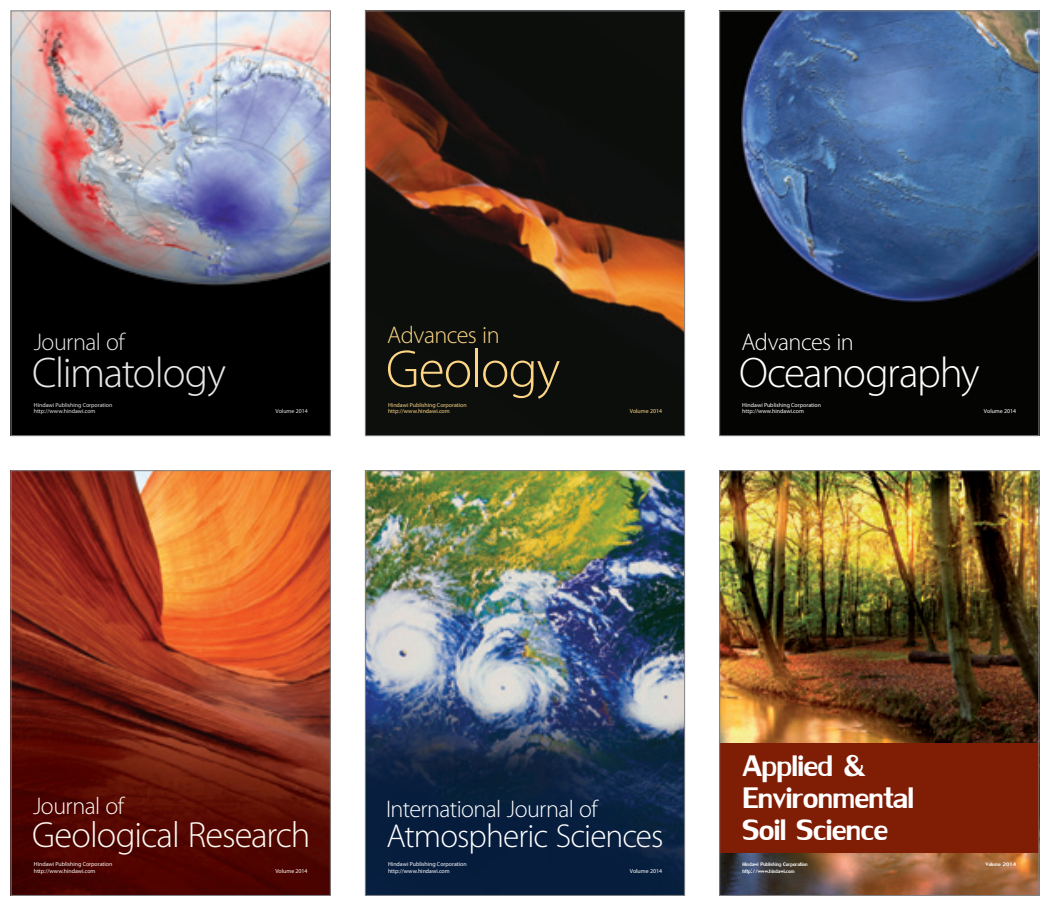
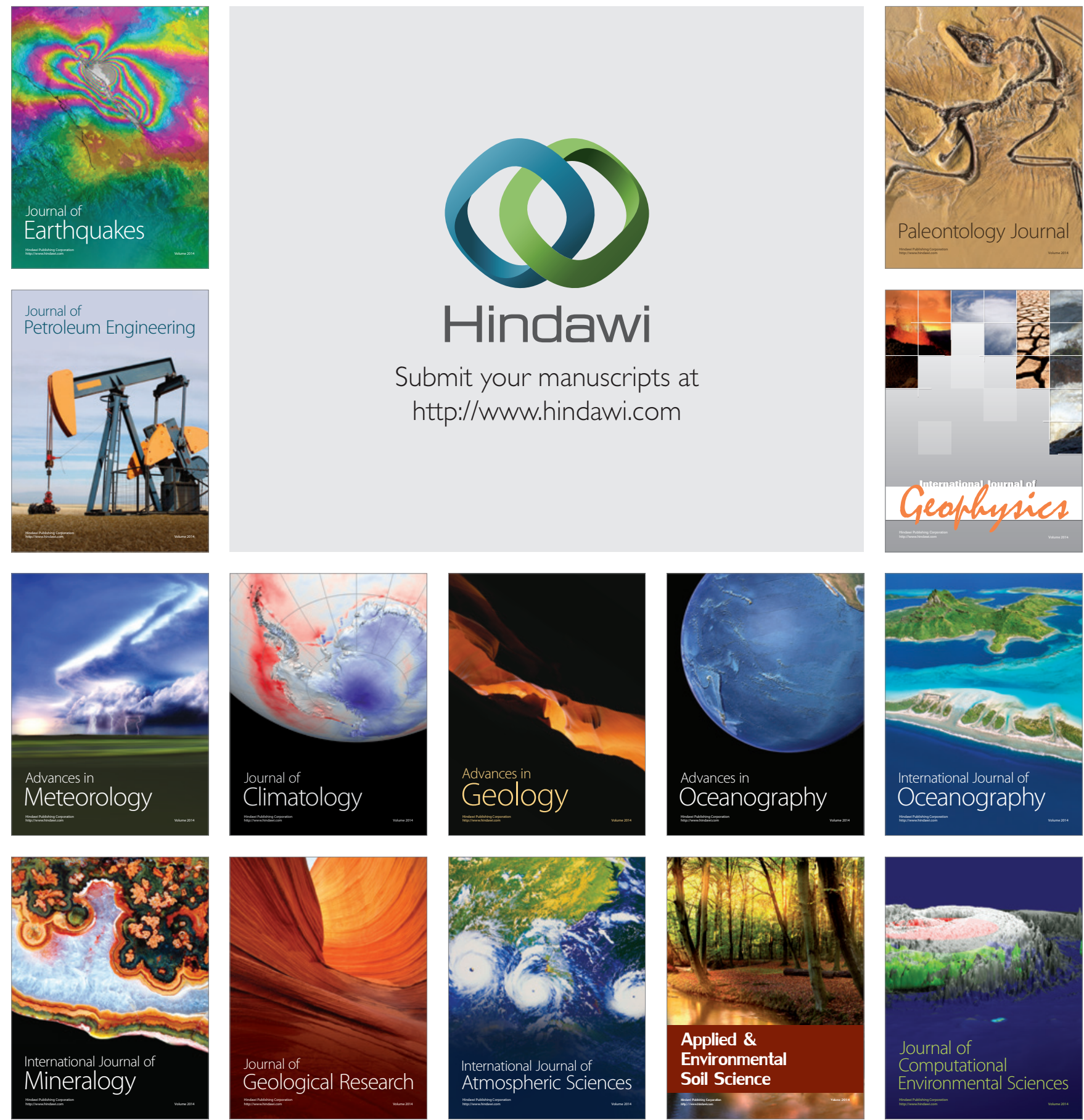